\title{
Inhaltsverzeichnis
}

Andreas Wirsching, Aleksandr Čubarjan

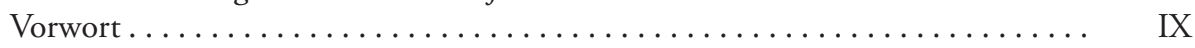

Jürgen Zarusky $28.4 .1958-4.3 .2019 \ldots \ldots \ldots \ldots \ldots \ldots \ldots \ldots \ldots \ldots \ldots \ldots \ldots \ldots \ldots$

Kolloquium „Deutsche und sowjetische Gesellschaften im ersten

Nachkriegsjahrzehnt. Traumata und Hoffnungen“

Bonn, 8. Juli 2016

\section{Natalia Timofeeva}

Der schwere Weg nach Hause: Die Resozialisierung der „Ostarbeiter“ nach ihrer

Rückkehr in die UdSSR 1945-1955 . . . . . . . . . . . . . . . . . . . . . . . . .

Angelika Königseder

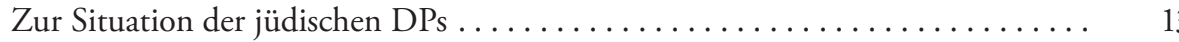

Stefan Troebst

Flucht, Verschleppung und Vertreibung von Deutschen 1944-1948 ..........

Vasilij Christoforov

Die Stimmung in der deutschen Bevölkerung in der Sowjetischen Besatzungszone

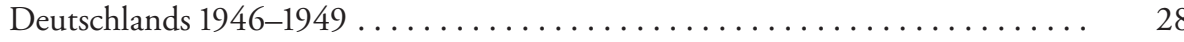

Andreas Malycha

Zur sozioökonomischen Situation in der Sowjetischen Besatzungszone (SBZ)/

DDR 1945 bis 1950 . . . . . . . . . . . . . . . . . . . . . . . . . . .

Thomas Schlemmer

Zwischen Hunger und Hoffnung. Ernährung und Alltag in (West-)Deutschland von der „Rationengesellschaft" zum „Wirtschaftswunder" $\ldots \ldots \ldots \ldots \ldots \ldots$

Beate Fieseler

Von der Waffe an die Wiege: Sowjetische Familien- und Geschlechterpolitik im Kontext des „Großen Vaterländischen Krieges"...................

Nina Vaškau

Vergangenheitsbewältigung: Der Wandel der Geschlechterrollen in der UdSSR im Nachkriegsjahrzehnt . . 
Till van Rahden

Sanfte Vaterschaft und Demokratie in der frühen Bundesrepublik ..........

Nachwuchsworkshop „Neue Perspektiven auf die deutsch-russische Beziehungs- und Verflechtungsgeschichte des 19. und 20. Jahrhunderts im globalen Kontext“ Heidelberg, 29. Oktober-2. November 2017

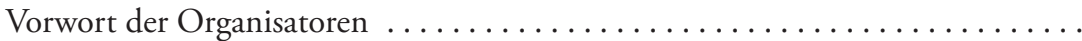

Andreas Hilger

Deutsch-russische Geschichte und Globalgeschichte . .

Nadezda Fichtner

Michail Rostovtzeffs Wissenschaftsbeziehungen zu deutschen Gelehrten Ende des 19. Jahrhunderts bis in die 1920er-Jahre . . . . . . . . . . . . .

Lilija Wedel

Kulturtransfer und Konsumkultur durch das Prisma der Werbung im Russischen

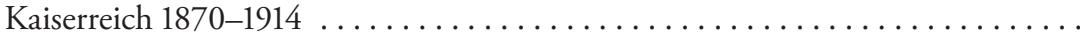

Igor' Barinov

Deutschbaltische Offiziere in der zaristischen Armee 1914-1918:

Zwischen Imperium und Nation $\ldots \ldots \ldots \ldots \ldots \ldots \ldots \ldots \ldots \ldots \ldots \ldots \ldots \ldots \ldots \ldots \ldots$

Leontij Lannik

Die Implementierung der Verträge von Brest-Litovsk als Problem

der Koalitionsstrategie der Mittelmächte.

Nataliya Kopcha

Politischer Mythos im Kulturtransfer: Politische Dostoevskij-Rezeption

bei Arthur Moeller van den Bruck . . . . . . . . . . . . . . . . . . . . . .

Yuliya von Saal

Sowjetische Kriegskindheiten: Überlegungen zu einem Forschungsfeld

Kristina Tanis

Beutefilme in der Sowjetunion: Besonderheiten des Kulturtransfers . .

Alexey Tikhomirov

Das visuelle Besatzungsregime im Ostdeutschland der Nachkriegszeit 1945-1961

Aleksei Sorokin

Das Sowjetunionbild der Bundeskanzler Adenauer und Brandt 
Alexander Friedman

West-Berlin als „Geheimtipp für jüdische Emigranten“. Die Stasi, der KGB und die jüdisch-sowjetische Community in West-Berlin in den 1970er-

und 1980er-Jahren

Die Autoren dieses Bandes . . . . . . . . . . . . . . . . . . . . . 273

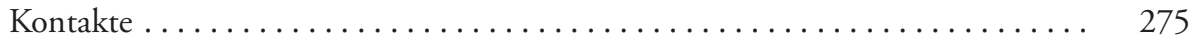


